HEALTHCARE DELIVERY

\title{
Social franchising primary healthcare clinics - a model for South African National Health Insurance?
}

\begin{abstract}
A K L Robinson
Andrew Robinson, MB ChB, DHSM, FCPHM, a public health medical specialist and health services executive, is currently Head: Clinical Services in North West Province, South Africa, responsible for clinical leadership, governance and delivery of quality health services at hospital and primary healthcare levels. Until recently he was Deputy Director-General of Health Services in North West, and he previously held positions with the Medical Research Council, the pharmaceutical industry and metropolitan government. He has also worked as a rural medical officer in South Africa and in general practice in the UK.
\end{abstract}

Corresponding author: A K L Robinson (arobinson@nwpg.gov.za)

This article describes the first government social franchise initiative in the world to deliver a 'brand' of quality primary healthcare (PHC) clinic services. Quality and standards of care are not uniformly and reliably delivered across government PHC clinics in North West Province, South Africa, despite government support, numerous policies, guidelines and in-service training sessions provided to staff. Currently the strongest predictor of good-quality service is the skill and dedication of the facility manager. A project utilising the social franchising business model, harvesting best practices, has been implemented with the aim of developing a system to ensure reliably excellent healthcare service provision in every facility in North West. The services of social franchising consultants have been procured to develop the business model to drive this initiative. Best practices have been benchmarked, and policies, guidelines and clinic support systems have been reviewed, evaluated and assessed, and incorporated into the business plan. A pilot clinic has been selected to refine and develop a working social franchise model. This will then be replicated in one clinic to confirm proof of concept before further scale-up. The social franchise business model can provide solutions to a reliable and recognisable 'brand' of quality universal coverage of healthcare services.

S Afr Med J 2015;105(7):531-534. DOI:10.7196/SAMJnew.7814

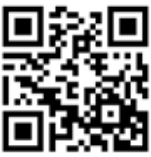

The idea of using franchise business principles to deliver health services in South Africa (SA) came to me while using the toilets at the Spur restaurant in Mahikeng, North West Province, in 2011 - why could such a busy restaurant maintain such clean ablutions, while the health services could not? The Mahikeng Spur bathroom sounds like an unlikely place for a 'light-bulb moment' regarding healthcare services delivery! However, it was this evidence of Spur's service reliability and functional quality systems that provoked my engagement with the Franchise Association of South Africa (FASA) in March 2012.

\section{The current situation}

In state health services, many primary healthcare (PHC) clinics run excellent services. However, there is no uniformity of standards across all clinics, nor are there effective mechanisms to implement and maintain standards. Well-run clinics are usually a result of the initiatives, inspiration, motivation and dedication of the facility manager rather than national, provincial or district office efforts or systems. The state can effectively establish excellent clinic facilities, but too often these subsequently perform poorly in respect of reliable, quality service provision.

An innovative and dynamic approach is necessary to shift the current situation to the standards that will be required from our clinics within the impending National Health Insurance (NHI). Rather than 'inventing' new models, the solution may lie in copying and adapting the various business principles utilised in the franchising concept and business model. Simply put, let us innovate within the health sector with old, but tried-and-tested, ideas.

\section{National Health Insurance}

The NHI Green Paper ${ }^{[1]}$ in August 2012 broadly outlined the planning, implementation and reform that aims to improve service provision and promote equity and efficiency to ensure that all South Africans have access to affordable, quality healthcare services, regardless of their socioeconomic status. This model of delivering health and healthcare services to the population is globally well accepted, and has been described and widely promoted by the World Health Organization (WHO) as 'universal health coverage. ${ }^{[2]}$

Ten districts were selected nationally for the NHI pilot. Dr Kenneth Kaunda District was selected as North West's pilot site. Subsequent to this, the National Department of Health (NDoH) held an NHI conditional grant workshop in Potchefstroom, North West, for the development and implementation of the NHI business plan (workshop presentation, April 2012 - unpublished). This presentation highlighted the opportunities for the study and testing of best practices, and pointed out that innovative approaches will be necessary to develop and enhance managerial, administrative and financial capacity in the facilities, and skills and competencies at district level. Once tested and approved, these would be scaled up across the health sector.

\section{A history and background of franchising}

There are many types of franchising, or replication businesses. The word 'franchise' has its origins in the French word 'franc', meaning 'freedom' or 'citizenship', and in essence means the granting of a privilege to a company to sell its goods or services in a prescribed manner.

Historically the franchising concept is not new, with rudimentary Chinese examples recorded as far back as 200 BC. The modern franchising concept developed in the 1860 s as a distribution system for the Singer sewing machine, followed soon after by the automotive industry. Franchising impetus increased after the end of World 
War II, notably in the fast-food sector. Businesses soon recognised that they could develop, control and dominate a market through the replication of successful business models via a network that could simultaneously gain market share.

The franchising industry in SA has grown at an incredible pace since 1945. It operates through nearly 30000 outlets, contributes $12 \%$ to the SA gross domestic product and, despite the economic downturn, ${ }^{[3]}$ provides stable employment to more than 500000 people.

The 'domino' effect of franchising, combined with strict operating procedures, enables a product, service or brand to spread rapidly through the marketplace, gaining public support. This public support is based on the confident expectation of uniformly high standards and quality of the product and/or service provision, no matter where the outlet is situated. Whether an individual enters a Kentucky Fried Chicken outlet in Soweto or downtown Seattle, he/she is assured of exactly the same customer experience.

Key players are the franchisor and the franchisee. The franchisor is the originator who develops and tests the concept and business systems, while the franchisee is granted the rights, through agreement, to operate under the well-developed brand name, adhering to set standards, methods, procedures, techniques and marketing plans.

Typically the franchisor retains control, and by working with dedicated owner-operators is able to increase the value of the brand while growing the business. The franchisee invests with minimal risk and enjoys access to a ready-made business having a recognised brand with the benefits of start-up support and training.

Established franchises typically consist of operational, finance, information technology (IT), human resources (HR) and marketing units, with the operational units comprising field staff, training and procurement sections. The field units play a pivotal role in ensuring the success of franchising outlets by supporting operational compliance and efficiencies. Training hubs have a key role in maintaining standards and in introducing new procedures and policies.

The field unit operates through face-to-face meetings and remote analysis using IT systems. The IT systems are enabled to monitor key operational functions and identify problems within the system.

A typical operational cycle entails stock procurement, production, sales and cash banked, with IT systems able to monitor invoices and stock, time on production and cost of sales. High-value items are monitored daily. For example, a burger outlet using 100 buns and ten meat patties in a cycle would be contacted by the field service manager as soon as the next day. Compare this with current PHC clinic function where, for example, 100 asthma inhalers might be dispensed per month for 10 asthma patients, with data at best recorded at some point, but gross supply chain inefficiencies still persisting.

In a franchise, the management information system is able to check operational compliance, efficiencies and variances from the operational manual. These integrated management systems are powerful tools ensuring the success of franchise brands.

In summary, the benefits of franchising are:

- Replication of a proven system and brand: consumer awareness

- Standardisation of products/services

- Economies of scale

- Rapid expansion to scale

- Centralised systems and controls - all facilities are measured, monitored and controlled in the same way, easing comparative performance based on established standards and operating procedures.

\section{Social franchising and healthcare}

The commercial franchising model has given rise to the relatively new concept of the social franchise. Its aim is to pursue social rather than commercial benefits, using franchising as the model for replication and distribution of the products and services of the organisation. Social franchises are businesses with a social mission, with sharing the defining feature distinguishing them from a classic business.

The first examples of social franchising emerged in the 1990s. ${ }^{[4]}$ There are now more than 83 social franchising programmes in 40 countries, which include over 75000 franchisees and over 60000 points of service delivery. ${ }^{[5,6]}$ This rapid rise is proving sustainable, and should be seen in the context of the emergence of a socioeconomic shift from 'self-interest' towards greater social responsibility. ${ }^{[7,8]}$

Social franchising and social enterprise should not be confused with philanthropy. They are not practical benevolence or charity, but the management of businesses with social goals in a manner that is businesslike and efficient. Most social franchise operations rely on grants and donor funds, and, with decreasing global funding streams, need to operate on commercial principles without the attainment of commercial goals. Other forms of social franchising include fractional franchising, where only a part of the services, commonly in health sectors such as sexual reproductive health (SRH), is offered. Conversion franchising, which will be used in the scale-up phase of the project I am about to describe, is where existing operations are to be converted to replicate the pilot model.

\section{Developing the social franchise model for North West Province's PHC \\ First steps}

Initially, with the FASA's assistance, a paradigm shift desk-top exercise was done to illustrate how the current status of PHC clinic services and a future envisioned social franchise clinic model could meet NHI needs. This is illustrated in Table 1.

The FASA executive was encouraged that government realised the potential of the franchise model to deliver health services and enthusiastically facilitated appropriate contacts with FASA-accredited consultants to develop the idea further. Various business models and practices in place in the franchising industry were examined, along with the concept of social franchising and whether these could be applicable or adaptable to the health services. This formed the basis of the business plan, which was finalised after inputs described in the project planning below. It became increasingly clear through the process that social franchising methodology could fulfil a number of basic NHI requirements in order to realise reliable access to quality health services for disadvantaged communities.

This thought leadership did, however, provoke serious head-winds from the National Ministry of Health, who initially perceived it as an attempt to privatise and profit from PHC. At that stage social franchising was considered to be a 'capitalist evil', thus advising the use of a different term. Despite this initial opposition, the quick adopters in the $\mathrm{NDoH}$ fortunately recognised the merits of the concept, and the social franchising term is now better understood and accepted, with many of its principles giving rise to its very promising Ideal Clinic programme. ${ }^{[9]}$ The next step was to introduce the social franchise model in the pilot district.

\section{Approval processes}

The business plan approval filtered through the provincial Department of Health's executive structures, with full support apart from an initial hesitancy over the term 'franchise. It was incorporated into the first NHI conditional grant business plan.

The procurement of a service provider with competency and a track record in social franchise development took some perseverance and stamina, withstanding legal challenges from less competent bidders, and enforced cancellation and readvertisement of the bid. 
Table 1. Social franchise - NHI clinic model

\begin{tabular}{|c|c|c|}
\hline & Current status & 'Brand PHC clinic' \\
\hline 1 & $\begin{array}{l}\text { Poor image of PHC clinics held by service users, resulting in } \\
\text { bypassing of PHC services and unnecessary congestion of hospital } \\
\text { services, with patients treated at inappropriate levels of care }\end{array}$ & $\begin{array}{l}\text { High acceptability by service users, with patients accessing services } \\
\text { at an appropriate level of care }\end{array}$ \\
\hline 2 & Variable number of patients from a geographical area & Fixed number of registered patients mapped from a specific area \\
\hline 3 & $\begin{array}{l}\text { Headed by a facility manager, usually an experienced professional } \\
\text { nurse, with no training on facility management }\end{array}$ & $\begin{array}{l}\text { Headed by a health professional, who is performance driven and } \\
\text { specifically trained and rewarded for this }\end{array}$ \\
\hline \multirow[t]{3}{*}{4} & $\begin{array}{l}\text { Run according to: } \\
\text { - Core standards } \\
\text { - Clinic supervision manual } \\
\text { - Various operational SOPs } \\
\text { - Various stock management systems } \\
\text { - Limited HR plans }\end{array}$ & $\begin{array}{l}\text { Clearly defined operations manual with training manual with } \\
\text { specific emphasis on: } \\
\text { - Business management administration, processes and procedures } \\
\text { - Support and training } \\
\text { - Efficient clinical stock management and procurement } \\
\text { - HR management systems } \\
\text { - Time management and allocations }\end{array}$ \\
\hline & All vary between facility and district. & - Asset management \\
\hline & $\begin{array}{l}\text { Other problems include stock outs, poor patient knowledge of } \\
\text { available services, badly maintained facilities, poorly managed } \\
\text { appointment and waiting times }\end{array}$ & - Facility/infrastructure maintenance \\
\hline 5 & $\begin{array}{l}\text { The full package of PHC services (including, for example, antenatal } \\
\text { services, HIV management, chronic care) is only provided if resources } \\
\text { exist and provision is of variable quality }\end{array}$ & Standardised, quality full package of care provided at each facility \\
\hline 6 & Poor data collection, management and usage & Data-driven management with clear outcomes \\
\hline 7 & Limited opportunities for job creation & Numerous opportunities for job creation at a local or rural level \\
\hline
\end{tabular}

Final approval came in November 2013, at least 15 months after the first submission to the Departmental Bid Adjudication Committee.

Further delays in the appointment of a service provider to effect necessary refurbishments, alterations and improvements to the pilot clinic to meet the social franchise structural requirements are currently hampering implementation.

\section{Project plan development and implementation}

Further research showed that the literature reflected rapid global adoption of the social franchising concept, largely for fractional or NGO-linked operations, primarily in the SRH sector. The only government-initiated social franchise was the Tinh Chi Em ('Sisterhood') network in Vietnam, with impressive scale outputs, ${ }^{[10]}$ and the Gold Star programme in Egypt ${ }^{[11]}$ both serving SRH services. Contact was made with Richard Feachem, Director of the University of California San Francisco's Global Health Group (CA, USA). This group directs the Private Sector Health Care Initiative, which in turn oversees the Social Franchise for Health (SF4H) organisation. He indicated that to his knowledge this would be the first government PHC social franchise project globally (R Feachem personal communication).

Field trips were made to the best-performing and one of the worst-performing clinics in North West to determine best practices, particularly factors that impacted positively on the patient and staff experience of the clinic. From in-depth analysis of all existing clinic-related operational documents, development of the operations manual is nearing completion. It will be digitised and updated annually. When the model is brought to scale it will be important to allow the manual to reflect necessary regional or area differences. The training manual development mirrored this process. Patient and stock management systems were developed to reduce the overwhelming paperwork and improve efficiencies.
All aspects of the clinic operations, which include clinical care, support services, health information, monitoring and evaluation and community engagement, were analysed in detail for their inclusion into the operations manual. This even included establishment and maintenance of the clinic garden towards a community nutritional role. The communications strategy included stakeholder workshops with senior departmental executives, local area managers, organised labour and communications staff.

It was important to select a well-performing clinic with a receptive facility manager and staff for the pilot clinic, and this selection was based on the findings of the field visits and the NHI pilot district selection.

A time-and-motion study done at the clinic highlighted the inordinate time the facility manager (a professional nurse) spent in meetings ( $>80 \%$ ) and on other management activities - this prompted the creation of an administrative position in the clinic to free the facility manager of this burden, to improve productivity and to optimise efficiency of the wage spend. Delegation, particularly of financial responsibilities and task shifting, would be important elements - the fractional franchising concept could even consider the consulting room, for example, as a cost centre. The local area manager's job description was adapted to match that of the franchise field service consultant, which is a pivotal position linking the franchisor and franchisee to support the successful operations of the facility.

A competition to select a clinic brand and logo was launched through the provincial consultative forums. The brand 'Atlarela' (to embrace/cup hands), with the logo 'Kalafo ka bokgabane' ('Healing through excellence'), was selected. These will be awarded to clinics that meet more than $80 \%$ of the set standards. Innovative performance rewards and incentives have been developed to reward the entire clinic workforce, linked to the maintenance and improvement of the branding status. 


\section{The way forward}

The operational launch is dependent on the refurbishment of the pilot facility. Refurbishment is an important aspect of the look and feel' of a franchised facility, addressing patient and staff experiences and needs. Unfortunately, delay in the bid process for this work has directly delayed the launch.

The launch process will follow on from staff training on the operations manual as well as training on basic franchising customer care, facility and staff management, stock and asset control, etc. This non-clinical training of the technical staff has resulted in a fundamental change in staff attitude, thereby enhancing the staff members' status as worthy service providers in their community. ${ }^{[10]}$

The launch will be carefully monitored and all operations reviewed in order to finalise the operations manual and reporting template before replication to another clinic in the NHI pilot district occurs. Once the replication has been completed, the model can be rapidly scaled to include all 360 clinics in the province and support the Ideal Clinic programme. It will be important to keep the brand current and fresh, with a process of unrelenting renewal to avoid the trap of 'if you always do what you always do, then you'll always get what you've always got' - there is still a lot to learn from successful franchise operations.

To bring PHC social franchising to scale in the province still requires an empowering change management process involving every employee at each clinic. This is not new in SA franchising, with a similar process of rapid scaling having been successfully undertaken in the private sector when Sasol managed to take over 100 outlets in 3 months. This rebranding and empowerment process ensures that each employee understands how the business functions, with cost-centre control reduced to the smallest units. This process needs to be initiated for PHC employees, and methods of doing so are currently being investigated.

\section{Related initiatives}

Within this model there could be an opportunity for a number of microenterprises and business opportunities to be created. This would have the potential to create jobs, particularly in rural areas, and enhance the sense of ownership of facilities. These enterprises could comprise:

- Cleaning services

- Garden services, vegetable and traditional medicine production

- Maintenance

- Security

- Water management

- Waste management and recycling

- Laundry

- Transport.

The departments of Trade and Industry and Economic Development, as well as the Youth Development agency and the South African State Information Technology Agency, could all provide resources to enable these initiatives. The NHI social franchise model could therefore have the ability to be a massive job creator on its own, particularly in impoverished rural areas. This model will also standardise the contribution to be made by general practitioners contracted to the NHI, as well as community health work and homebased care. Non-profit organisations could be contracted to deliver fractional franchise services such as SRH or HIV care (FASA personal communication).

\section{Conclusion}

Franchising is a long-established business model that provides a sound basis for investigating and initiating changes to the way services are structured and managed, and fits the new NHI structural changes to the SA health system. Implementing a social franchise model for PHC facilities has the following potential advantages:

- A standardised look and feel would contribute to positive brand perceptions. It would contribute to a positive image and experience in the clinics. Patients would know what quality care to expect at every branded clinic.

- Greater focus on operational and administrative efficiency would increase quality of care and service delivery.

- Standardisation of operational and administrative systems would free up valuable time for staff to focus on patient care and outcomes.

- Formalisation and standardisation of operational policies would enhance ease of reference and compliance.

- Increased efficiency would lead to cost containment and extend the impact of funding streams.

- Standardisation of budget management and possible automation of the ordering process would contribute to cost containment.

The North West Provincial Health Department's social franchising project for PHC is the first government-led social franchise initiative globally, and is currently being piloted in Dr Kenneth Kaunda District.

This social franchise business model, if successfully implemented, also has potential for other aspects of health service delivery such as hospital care, and for use within the private sector, particularly when considering the contracting of private sector services into the NHI. If the model can be implemented successfully, there is vast potential to use it more widely to improve services in other government sectors such as education, transport, housing and agriculture.

The easy part of this project is to develop the pilot social franchise clinic and to replicate it. The more challenging part will be to shift the mindset of the central sectors of healthcare to act like a franchisor, and actively support these PHC clinics in their effort to succeed.

All those consulted in the health sector think this is a 'great idea' that makes sense. However, a paradigm shift must happen with their verbal support translating into action. After all:

Inputs $\times$ provider practice $=$ impact and outcomes

Delivery of universal health coverage, particularly to the rural poor, is a matter of urgency. Can we create a health service delivery ecosystem that will combine currently available resources here and now? As a model, social franchising for health shows the way.

Acknowledgements. The author would like to thank all who have participated in the development of this social franchise PHC clinic model, as well as those who assisted with the editing of this publication.

1. Ministry of Health. National Health Insurance in South Africa. Policy Paper. Government Notice 657. Government Gazette No. 34523, 12 August 2011.

World Health Organization. Universal health coverage. http://www.who.int/universal_health_ coverage/en/ (accessed 8 January 2015).

Illetschko K. FASA Directory: How To Franchise Your Business. 6th ed. Bruma, Gauteng: Franchise Association of South Africa, 2012.

4. Montagu D. Franchising of health services in developing countries. Health Policy Plan 2002;17(2):121 130. [http://dx.doi.org/10.1093/heapol/17.2.121]

5ontagu D. Overview of clinical social franchising. July 2013 (ppt). http://www.sf4health.org research-evidence/presentations (accessed 21 June 2015).

6. Viswanathan R, Schatzkin E, Sprockett A, Montagu D. Overview of clinical social franchising and finding from the 2014 clinical social franchising compendium. September 2014 (ppt). http://www.sf4health.org sites/sf4health.org/files/wysiwyg/2014CompendiumResults_V2.pptx (accessed 8 January 2015)

Du Toit A. Social franchising as organisational format - an overview. In: Alon I, ed. Social Franchising Basingstoke, UK: Palgrave Macmillan, 2014:8-32.

8. Sauer JB. Unnatural virtues for well living: Social economy, civitas, and public philosophy. Int J Soc 8. Sauer JB. Unnatural virtues for well living: Social economy, civitas, and public
Econ 1997;24(11):1172-1190. [http://dx.doi.org/10.1108/03068299710193552]

Fryatt R, Hunter I, Matsoso P. Innovations in primary health care: Considerations for National Health Fryatt R, Hunter J, Matsoso P. Innovations in primary health care: Considerations for Na

10. Government social franchising: Using private sector approaches to improve the public sector provision of reproductive healthcare in Vietnam. http://mariestopes.org/sites/default/files/MSI\%20 Innovations\%20-\%20Viet\%20Nam_4.pdf (accessed 8 January 2015).

11. Egypt's Gold Star Quality Program Wins Clients and Communities. http://ccp.jhu.edu/documents/4. pdf (accessed 8 January 2015).

Accepted 9 March 2015. 